\title{
ESTUDO DA INFLUÊNCIA DOS TRATAMENTOS TÉRMICOS DE RECOZIMENTO PLENO E ESFEROIDIZAÇÃO NAS CURVAS DE ESCOAMENTO A FRIO DO AÇO ABNT I 045
}

\author{
Leonardo Haerter dos Santos 1,2 \\ Lírio Schaeffer ${ }^{2}$ \\ Suelen Quinot Fortunato ${ }^{3}$ \\ José Lesina Cézar ${ }^{4}$ \\ Miguel Afonso Flach '
}

\section{Resumo}

Uma das características mais importantes para a definição de um processo de conformação mecânica a frio é a resistência que o material oferece à deformação. Essa resistência à deformação é definida pelas curvas de escoamento a frio do material, que são função, além da composição química do material, da microestrutura que ele apresenta. Nesse artigo um aço ABNT 1045 comercial, foi submetido aos tratamentos térmicos de recozimento pleno, e de esferoidização, sendo, posteriormente, ensaiado para determinação de suas curvas de escoamento. Após os ensaios, verificou-se que o material recozido apresentou uma curva de escoamento inferior à do material bruto de laminação, enquanto o material esferoidizado apresentou a menor resistência à deformação entre todos. Dessa forma, a esferoidização é o tratamento térmico mais recomendado quando, no forjamento a frio, deseja-se altos graus de deformação em materiais considerados de baixa conformabilidade, como é o caso do aço ABNT 1045.

Palavras-chave: Curvas de escoamento a frio; Esferoidização; Recozimento pleno.

\section{STUDY OF FULL ANNEALING AND SPHEROIDIZING HEAT TREATMENTS IN THE ABNT I 045 STEEL COLD FLOW STRESS CURVES}

\begin{abstract}
One of the most important characteristics for the definition of a cold forming process is its forming resistance. The forming resistance is defined by the material cold flow stress curves, which are function, besides the chemical composition, of its microstructure. In this paper, a commercial ABNT 1045 steel was subjected to the full annealing and spheroidizing heat treatments and, after this, tested for flow stress curves. After the tests, it was found that the annealed material presented a lower flow stress curve than the hot rolled material, while the spheroidized material presented the least resistance to deformation among all. Thus, spheroidizing is the most recommended heat treatment when, during cold forging, high degrees of deformation are desired in materials considered to be of low formability, such as ABNT 1045 steel. Keywords: Cold Flow Stress Curves; Spheroidizing; Full annealing.
\end{abstract}

\section{INTRODUÇÃO}

Os processos de conformação mecânica a frio, em função das características de seus produtos finais, tais como o acabamento superficial e a precisão dimensional, têm sido bastante estudados. Esses processos, apesar de apresentarem muitas vantagens, quando comparados aos processos de conformação a quente, apresentam algumas características que tornam mais complexa sua execução. Uma dessas características, que pode ser destacada, é a força

'Departamento de Engenharia Mecânica, Universidade Luterana do Brasil - ULBRA, Canoas, RS, Brasil. E-mail: leonardo.ulbra@gmail.com ${ }^{2}$ Programa de Pós-graduação em Engenharia de Minas, Metalúrgica e de Materiais - PPGE3M, Universidade Federal do Rio Grande do Sul - UFRGS, Porto Alegre, RS, Brasil.

${ }^{3}$ Universidade Luterana do Brasil - ULBRA, Canoas, RS, Brasil.

${ }^{4}$ Programa de Pós-graduação em Engenharia de Materiais e Processos Sustentáveis - PPGEMPS, Universidade Luterana do Brasil - ULBRA, Canoas, RS, Brasil. 
necessária para a realização da deformação, que costuma ser bem maior do que a necessária em um processo de conformação a quente.

Esse fato é devido ao processo de encruamento pelo qual a peça, que está sendo deformada, passa durante a deformação. $O$ que não acontece quando o processo é feito a quente, pois, concomitante com o encruamento, a microestrutura é recristalizada, através dos processos dinâmicos de recuperação e recristalização.

A medida desse endurecimento, devido ao encruamento, pode ser descrita pela equação de Hollomon, como função da deformação à qual a peça é submetida [I], definindo assim, a chamada curva de escoamento. Alguns fatores são decisivos para a determinação do comportamento da curva de escoamento, tais como, a composição química do material, e a sua microestrutura prévia ao processo de conformação [2].

Quanto à composição química, existem alguns materiais que são mais indicados para a deformação a frio, por possuírem, mesmo com estrutura bruta de laminação, uma certa dutilidade à temperatura ambiente. Quanto à microestrutura, verifica-se que alguns tipos de tratamentos térmicos, usualmente variações do recozimento, tendem a aumentar essa dutilidade, reduzindo, assim, a força necessária para a realização de uma mesma deformação. Ou ainda, aumentando o limite de deformação para um determinado material.

Dentro desse contexto, o objetivo desse trabalho é determinar experimentalmente as curvas de escoamento de um aço $A B N T$ 1045, que é considerado um material de baixa conformabilidade [3] em três estados distintos: bruto de laminação; recozido (recozimento pleno); e, esferoidizado.

\section{MATERIAIS E MÉTODOS}

O material utilizado foi um aço ABNT 1045 comercial, cuja composição química informada pelo fornecedor é apresentada na Tabela $\mathrm{I}$.

\section{I Preparação dos Corpos de Prova}

Foram utilizados três corpos de prova, todos retirados da mesma barra, que foram submetidos aos tratamentos térmicos, como segue: o primeiro dos corpos de prova foi mantido no estado bruto de laminação, o segundo foi submetido ao processo de recozimento pleno, e o terceiro foi submetido ao processo de esferoidização.

Tabela I. Faixa de composição química do aço ABNT I045 [4]

\begin{tabular}{cccc}
\hline Elemento & Carbono (C) & $\begin{array}{c}\text { Manganês } \\
(\text { Mn) }\end{array}$ & Silício (Si) \\
\hline Mínimo (\%) & 0,43 & 0,60 & 0,15 \\
Máximo (\%) & 0,48 & 0,90 & 0,30 \\
\hline
\end{tabular}

Os processos de tratamento térmico foram realizados em um forno de laboratório, utilizando as seguintes sequências de processo:

- Recozimento pleno: o corpo de prova foi aquecido até a temperatura de $860^{\circ} \mathrm{C}$, mantido nessa temperatura por duas horas, e, posteriormente, resfriado dentro do forno a uma taxa de, aproximadamente, $50^{\circ} \mathrm{C} / \mathrm{h}$, até uma temperatura inferior a $500^{\circ} \mathrm{C}$;

- Esferoidização: o corpo de prova foi aquecido até uma temperatura de $770^{\circ} \mathrm{C}$, mantido nessa temperatura por quatro horas, depois resfriado dentro do forno até a temperatura de $690^{\circ} \mathrm{C}$, na qual foi mantido por mais seis horas, para depois ser resfriado dentro do forno a uma taxa de, aproximadamente, $50^{\circ} \mathrm{C} / \mathrm{h}$, até uma temperatura inferior a $500^{\circ} \mathrm{C}$.

Os corpos de prova, depois de tratados, foram usinados para dar origem, cada um, a três corpos de prova cilíndricos, com diâmetro de $10 \mathrm{~mm}$ por $15 \mathrm{~mm}$ de altura.

\subsection{Procedimento Experimental}

Nos três corpos de prova de cada um dos três estados, foram realizados ensaios de compressão, com o objetivo de se obter curvas relacionando o deslocamento das matrizes, planas e paralelas, com a força aplicada. Esses ensaios foram realizados em uma máquina universal de ensaios EMIC DL20000, e a velocidade de deformação $(\dot{\varphi})$ utilizada foi de $0,01 \mathrm{~s}^{-1}$.

Para que seja evitado o efeito do "embarrilhamento", é necessária a lubrificação do contato entre as matrizes e os corpos de prova. Neste trabalho, a lubrificação foi feita utilizando uma fita de politetrafluoretileno (Teflon ${ }^{\circledR}$ ).

Após a construção da curva de deslocamento $x$ força, desprezando-se o efeito do "embarrilhamento", utilizou-se a lei da constância de volume (Equação I) para, a partir do valor da área da seção transversal inicial $\left(A_{0}\right)$, da altura inicial $\left(h_{0}\right)$, e da altura instantânea $\left(h_{i}\right)$ obter-se o valor da área de seção transversal instantânea $\left(A_{i}\right)$.

$$
A_{0} \cdot h_{0}=A_{i} \cdot h_{i}
$$

Dividindo-se a força instantânea $\left(F_{i}\right)$, pela área instantânea, foi calculada a tensão verdadeira instantânea $\left(\mathrm{kf}_{\mathrm{i}}\right)$, como mostra a Equação 2 [5].

$$
k f_{i}=\frac{F_{i}}{A_{i}}
$$

Com os valores da altura instantânea e da altura inicial, foram calculadas as deformações verdadeiras instantâneas (Equação 3), e, então, construída a curva $\mathrm{kf} \times \varphi$.

$$
\varphi_{i}=\ln \left(\frac{h_{i}}{h_{0}}\right) .
$$


Em seguida, destacando-se da curva anterior a regiãoorrespondente à deformação plástica $(\varphi>0,002)$ foi traçada a curva log $k f x \log \varphi$. Da linearização dessas curvas, obteve-se as equações das retas, no formato da Equação 4, que serviram como para a determinação dos coeficientes da equação de Hollomon (Equação 5).

$$
\begin{aligned}
& \log k f=n \cdot(\log \varphi)+\log C \\
& k f=C \cdot \varphi^{n}
\end{aligned}
$$

\section{RESULTADOS}

Cada corpo de prova deu origem a uma curva de tensão verdadeira $x$ deformação verdadeira, que foram agrupadas de acordo com a condição inicial, e são mostradas

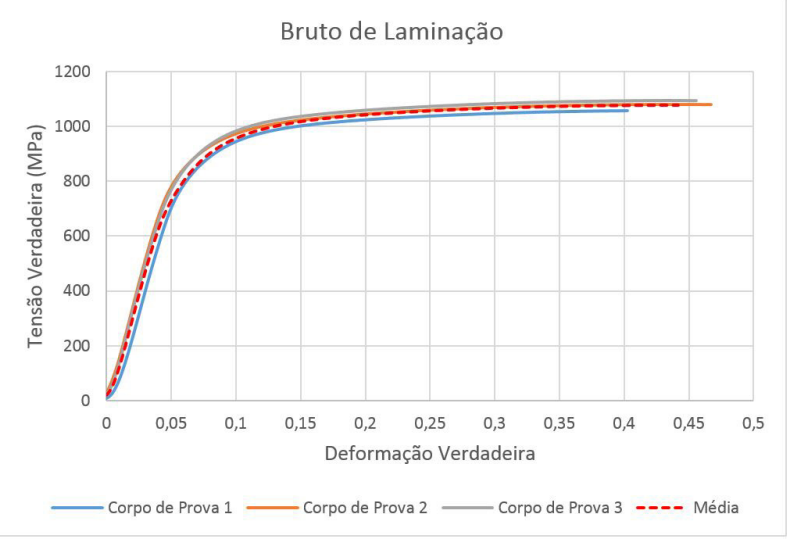

Figura I. Curvas tensão verdadeira $x$ deformação verdadeira para o estado bruto de laminação.

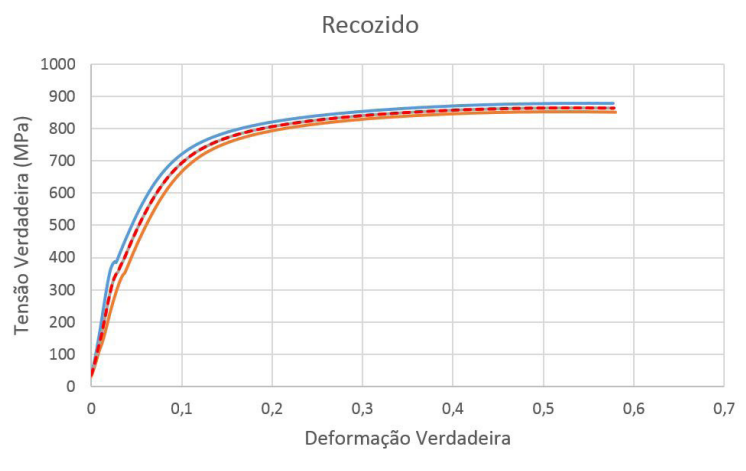

Figura 2. Curvas tensão verdadeira $x$ deformação verdadeira para o estado recozido. nas Figuras I, 2 e 3. A quarta curva em cada figura representa os valores médios das três curvas ensaiadas.

A Figura 4 mostra apenas as curvas médias, que são as que foram utilizadas no restante do trabalho.

Pode-se observar nas curvas da Figura 4, que, para que se obtivesse uma mesma deformação plástica, a força necessária foi maior para o material bruto de laminação, do que para o material recozido, e esta última, por sua vez, maior do que a necessária para deformar o material esferoidizado.

A Figura 5 mostra os resultados experimentais em um gráfico bi-logarítmico. Para que possa ser aplicada a Equação 4 cada uma das curvas foi aproximada por uma linha reta, representadas como linhas pontilhadas na Figura 5.

Da mesma forma que no gráfico da Figura 4, verifica-se que a curva referente ao material bruto de laminação apresenta-se acima das outras duas, ficando o material recozido em uma posição intermediária, e o esferoidizado abaixo dos demais.

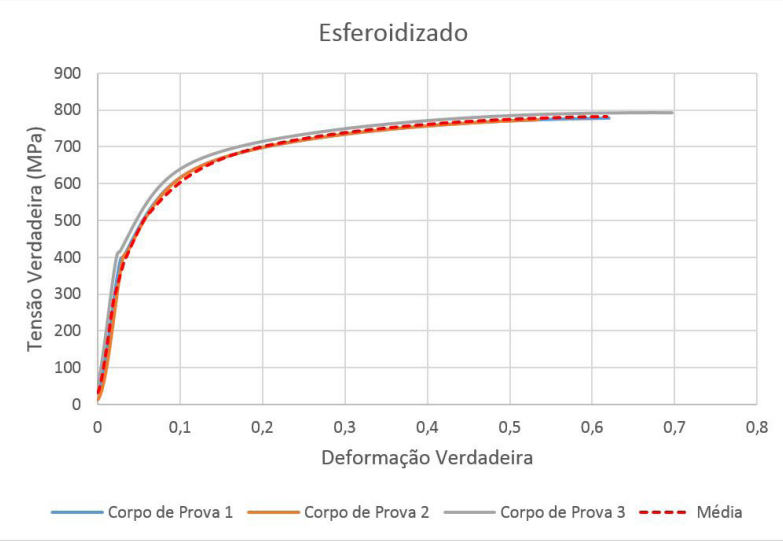

Figura 3. Curvas tensão verdadeira $x$ deformação verdadeira para o estado esferoidizado.

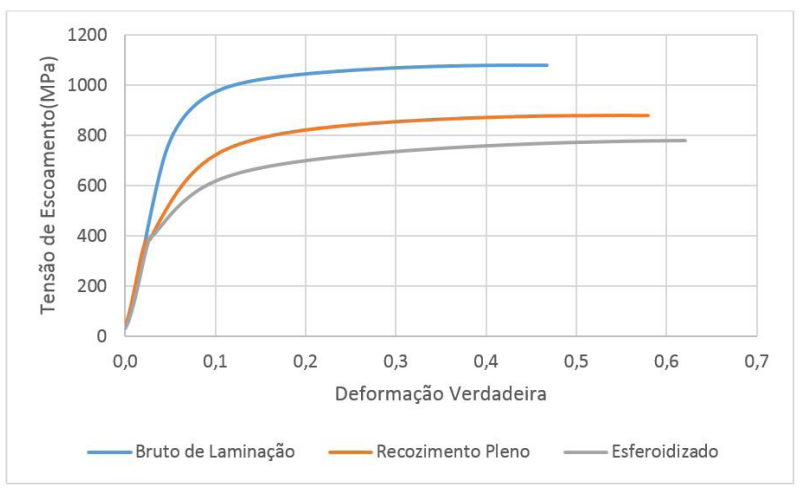

Figura 4. Curvas tensão verdadeira $x$ deformação verdadeira para os materiais ensaiados. 
Da linearização dessas curvas, obteve-se a equação de Hollomon para cada um dos três casos, conforme segue:

- Material Bruto de Laminação (Equação 6)

$$
k f=1117,46 . \varphi^{0,041}
$$

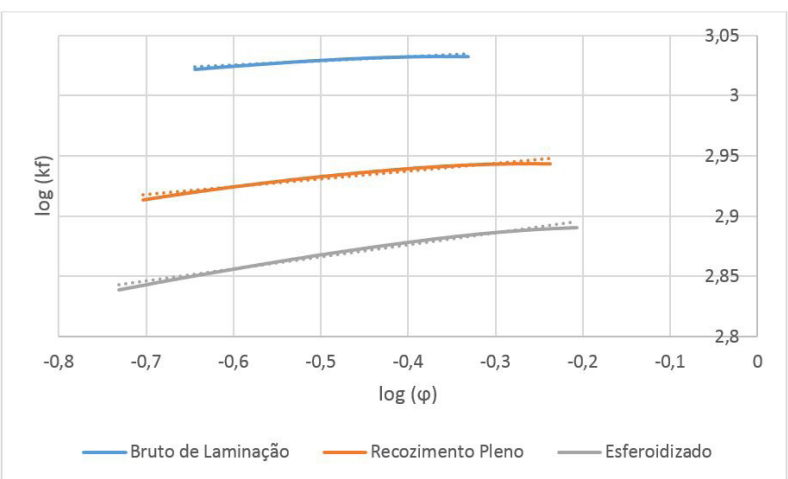

Figura 5. Curva log $(k f) \times \log (\varphi)$ para os materiais ensaiados.

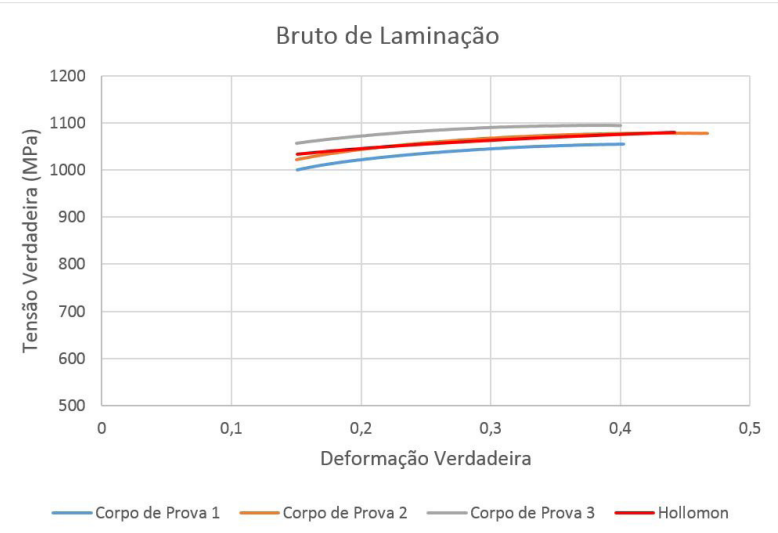

Figura 6. Comparação dos valores experimentais com a aproximação de Hollomon para o estado bruto de laminação.

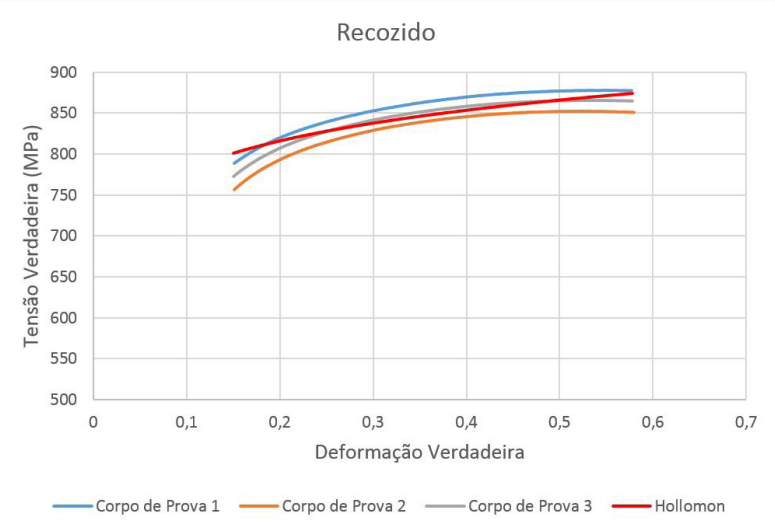

Figura 7. Comparação dos valores experimentais com a aproximação de Hollomon para o estado recozido.

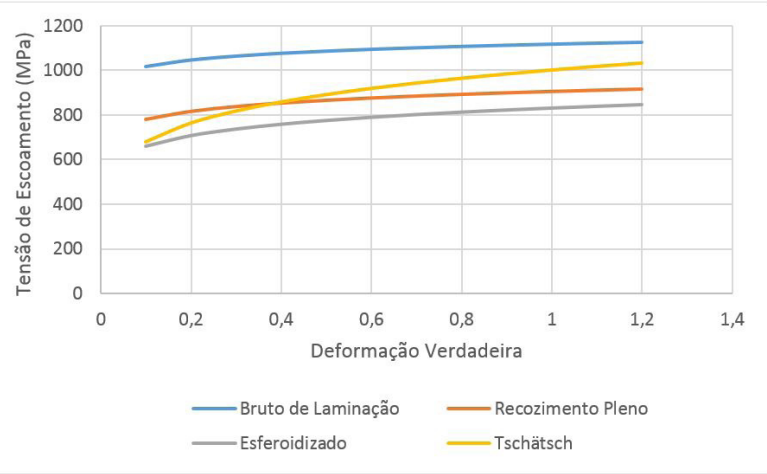

Figura 9. Gráfico comparativo dos resultados obtidos com os valores de bibliografia.

- Material Tratado para Recozimento Pleno (Equação 7)

$$
k f=906 . \varphi^{0,065}
$$

- Material Tratado para Esferoidização (Equação 8)

$$
k f=830 . \varphi^{0,099}
$$

Nas Figuras 6, 7 e 8 são mostradas as curvas obtidas através da aproximação de Hollomon comparadas com as curvas obtidas experimentalmente.

Tschätsch [6] apresenta uma curva para o aço Ck45 submetido ao recozimento pleno. A equação de Hollomon para essa curva é a seguinte (Equação 9):

$$
k f=1000 \cdot \varphi^{0,167}
$$

Colocando-se as quatro curvas de Hollomon, as três obtidas a partir de valores experimentais mais a de Tschätsch, em um mesmo eixo de coordenadas, obteve-se o gráfico da Figura 9.

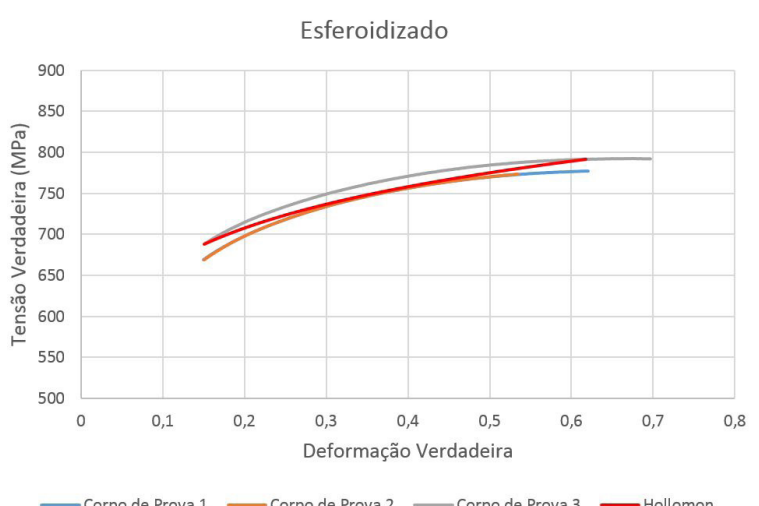

Figura 8. Comparação dos valores experimentais com a aproximação de Hollomon para o estado esferoidizado.

Tecnol. Metal. Mater. Miner., São Paulo, v. 15, n. I, p. 75-79, jan./mar. 2018 


\section{DISCUSSÃO}

As curvas mostradas nos gráficos das Figuras 6,7 7 8 mostram que a aproximação de Hollomon é representativa do comportamento experimental. Observando o gráfico da Figura 9, verifica-se que a curva de Tschätsch [6] cruza-se com a curva do material recozido quando a deformação é de aproximadamente 0,35 , porém, tem uma taxa de variação maior do que a obtida no ensaio. Essa diferença é função de um maior valor do coeficiente de encruamento (n), 0, 165 de Tschätsch contra 0,065 determinado experimentalmente. É impossível determinar de forma assertiva a causa dessa diferença, visto que $o$ autor não apresenta detalhes sobre a microestrutura do material utilizado por ele. Porém, é importante salientar que o aço DIN Ck45 é, por definição, obtido a partir de minério, o que não é o caso do $A B N T$ 1045 ensaiado, que é proveniente de reciclagem.

É possível observar, também, que a curva referente ao aço bruto de laminação encontra-se acima de todas as outras, demonstrando que é o pior estado inicial, entre todos, se o objetivo é utilizá-lo como matéria prima para a conformação a frio. Enquanto o material esferoidizado, apresenta-se no extremo oposto, como a curva mais baixa entre todas.

Analisando alguns pontos individuais, percebe-se que todos os pontos plotados no gráfico, para o aço recozido, encontram-se abaixo do ponto correspondente ao início da deformação do aço bruto de laminação. E para o aço esferoidizado, a tensão correspondente à deformação de $120 \%$ é equivalente à tensão apresentada pelo aço recozido a uma deformação muito inferior, de $35 \%$.

\section{CONCLUSÕES}

Com a observação dos resultados, conclui-se que a realização de tratamentos térmicos prévios é de grande importância para o processo de forjamento a frio. Sendo uma alternativa interessante quando deseja-se reduzir o esforço durante a deformação em aços que, como o ABNT 1045, são considerados de baixa conformabilidade. Observa-se, também, que o tratamento de esferoidização, embora mais demorado e, portanto, mais caro, apresenta os melhores resultados entre os estados analisados.

\section{REFERÊNCIAS}

I Vafaeian S, Fattah-alhosseini A, Mazaheri Y, Keshavarz MK. On the study of tensile and strain hardening behavior of a thermomechanically treated ferritic stainless steel. Materials Science and Engineering A. 2016;(669):480-490.

2 Schaeffer L. Manufatura por conformação mecânica. Porto Alegre: Imprensa Livre; 2016.

3 Billingmann J, Feldmann HD. Estampado y prensado a máquina: manual sobre conformado en frio y en caliente de aceros y metales no férreos. Barcelona: Reverté; 2002.

4 ArcelorMittal. Catálogo: guia do aço. São Paulo: Arcelor Mittal; 2013.

5 Oliveira ASM, Böesch PR Jr, Rodrigues DA, Martins V, Schaeffer L. Obtenção da curva de escoamento a frio para o aço AISI 4I 40 através do ensaio de compressão. In: Associação Brasileira de Metalurgia, Materiais e Mineração. Anais do $67^{\circ}$ Congresso da ABM. Rio de Janeiro. São Paulo: ABM; 20I2. p. 31-4I.

6 Tschätsch H. Metal forming practise. Berlin: Springer; 2005.

Recebido em: 30 Jan. 2017

Aceito em: 3 Maio 2017 